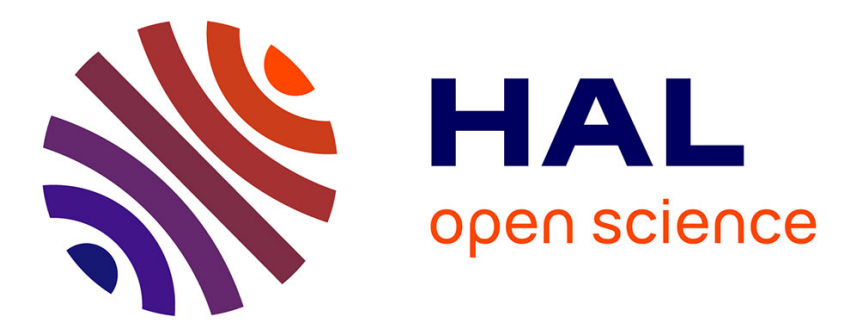

\title{
Feeding behaviour and diet choices of cattle with physical and temporal constraints on forage accessibility: An indoor experiment
}

Cécile Ginane, M. Petit

\section{- To cite this version:}

Cécile Ginane, M. Petit. Feeding behaviour and diet choices of cattle with physical and temporal constraints on forage accessibility: An indoor experiment. Animal Science, 2005, 81 (1), pp.3-10. 10.1079/ASC41230003 . hal-02680765

\section{HAL Id: hal-02680765 \\ https://hal.inrae.fr/hal-02680765}

Submitted on 31 May 2020

HAL is a multi-disciplinary open access archive for the deposit and dissemination of scientific research documents, whether they are published or not. The documents may come from teaching and research institutions in France or abroad, or from public or private research centers.
L'archive ouverte pluridisciplinaire HAL, est destinée au dépôt et à la diffusion de documents scientifiques de niveau recherche, publiés ou non, émanant des établissements d'enseignement et de recherche français ou étrangers, des laboratoires publics ou privés.

\section{다(1)(2)}

Distributed under a Creative Commons Attribution - ShareAlikel 4.0 International 


\section{Feeding behaviour and diet choices of cattle with physical and temporal constraints on forage accessibility: An indoor...}

Article · August 2005

DOI: 10.1079/ASC41230003

CITATIONS

READS

4

2 authors, including:

\section{Cécile Ginane}

French National Institute for Agricultural Research

48 PUBLICATIONS 425 CITATIONS

SEE PROFILE 


\title{
Feeding behaviour and diet choices of cattle with physical and temporal constraints on forage accessibility: an indoor experiment
}

\author{
C. Ginane ${ }^{\dagger}$ and M. Petit \\ INRA, Unité de Recherches sur les Herbivores, Centre de Theix, 63122 Saint-Genès-Champanelle, France \\ †E-mail: ginane@sancy.clermont.inra.fr
}

\begin{abstract}
An indoor choice experiment was conducted to assess the extent to which heifers offered two forages of different quality will attempt to consume the better quality forage when the weight/number of constraints applied on its harvesting increase. The experiment involved six Salers heifers, a leafy $(L)$ and a coarse $(C)$ hay, and two combined or single accessibility constraints. A physical constraint consisted of reducing the prehensibility of $L$ by covering the trough with a steel grid of either $4 \mathrm{~cm}$ or $6 \mathrm{~cm}$ mesh size ( $L 4$ or $L 6 \mathrm{v}$. L $\infty$ for no grid). A temporal constraint limited the daily access time to both hays to $4 \mathrm{v}$. $24 \mathrm{~h}$. The hays were either offered alone or together over 2-week periods. Dry-matter intake and feeding time were recorded daily.

As expected, the physical constraint (only L4 was efficient) made the heifers decrease their choice (proportion of feeding time or intake) for $L$ regardless of access time, whereas the temporal constraint had no significant effect on choice. The heifers greatly modulated their intake rate of $L$ even under strong physical constraint (L4), and then unexpectedly managed to ingest $L$ faster than $C$. This emphasizes their motivation to keep ingesting the better quality forage, and underlines the difficulties in comparing diet choices with the optimal foraging theory predictions based on the relative values of a behavioural component subject to large variation, i.e. intake rate. In a very constraining situation (L4 and 4$h$ access), heifers made a choice that allowed them to increase their total daily digestible organic matter (DOM) intake compared with L4 or C offered alone because of an inverse relationship between feeding time and intake rate on L4. They did not however maximize their total daily DOM intake in a less constraining situation ( $L \infty$ or $L 6$ and $C$, with 4-h access), since they did not consume $L$ exclusively and showed a marked preference for a mixed diet.
\end{abstract}

Keywords: cattle, feeding behaviour, food intake, food preferences.

\section{Introduction}

Experiments conducted indoors involving artificiallymodified foods (Kyriazakis and Oldham, 1993; Kenney and Black, 1984), reconstructed swards (Black and Kenney, 1984; Laca et al., 1992) or devices creating spatial heterogeneity (Dumont and Petit, 1995; Scott and Provenza, 1998) have proved to be useful tools for dealing with issues on herbivore grazing behaviour. On the more specific topic of diet choices, indoor experiments carry many advantages. They allow good control of the relative quality of offered forages over time, accurate measurement of intakes and intake rates on each forage, and precise evaluation of the animals' behavioural adjustments under constraints (such as change of intake rate).

This experiment makes reference to the context of extensive grazing, where the low grazing pressure leads to a mosaic of often-grazed short/low-biomass vegetative patches and tall/high-biomass maturing reproductive patches (Willms et al., 1988; Coughenour, 1991). This confronts herbivores with a trade-off between long term rate of energy assimilation (implying sufficient rate of passage, i.e. quality) and short term rate of food intake (quantity) (Gordon and Illius, 1992; Newman et al., 1995; Wilmshurst et al., 1995).

To mimic indoors the low height of a vegetative sward, we constrained the availability of a good quality (leafy) hay by covering the trough with a steel grid of variable mesh size, and we offered this hay in a choice situation with another hay of lower quality (coarse) but freely available. Moreover, as increasing feeding time is a known compensatory mechanism of a reduced intake rate due to low forage accessibility (Allden and Whittaker, 1970; Penning, 1986; Penning et al., 1991), including in choice situations (Ginane et al., 2003), we also constrained the daily available feeding time. One original aspect of this study lies in combining two accessibility constraints -one physical, one temporaland testing their effects on heifers' ingestive and choice behaviours between two forages of different quality. Many previous experiments have investigated the effects of a 


\section{Ginane and Petit}

temporal constraint on the ingestive behaviour of ruminants offered only one forage (Hidari, 1981; lason et al., 1999 (sheep); Romney et al., 1996 (goats); Suzuki et al., 1970; Chilibroste et al., 1997 (cattle)), but few have tested the effects of a temporal constraint on diet choice (Laca et al., 1997 (sheep)), especially between forages differing in stage of maturity (Ginane and Petit (2005) (cattle)).

The aim of the study was to assess the extent to which heifers will attempt to maintain their choice for the leafy hay, when the weight of constraints applied on its harvesting increases. We predicted that (i) with zero or low physical constraint, the choice would be almost exclusively in favour of the leafy hay, all the more as the access time is restricted, and that it would decrease with the application of the physical constraint, (ii) the restriction of access time would then increase the choice for the leafy hay when freely available (no grid), whereas it would decrease with the most constraining grid, and (iii) consequently, the lowest choice for the leafy hay would be when the constraints are combined. These hypotheses are in accordance with the theoretical optimization approach stating that animals are supposed to prefer the food providing the highest rate of energy (digestible organic matter) intake (Stephens and Krebs, 1986).

\section{Material and methods}

The experiment was carried out at the experimental farm in Laqueuille (Puy-de-Dôme, France) from mid February to mid June 2000.

\section{Animals and forages}

We used six 18-month-old Salers heifers weighing 432 (s.d. 15) $\mathrm{kg}$ at the beginning and 449 (s.d. 7) $\mathrm{kg}$ at the end of the experiment. From 15 days before the beginning of the experiment, the heifers were housed in individual pens, isolated from each other by barriers that allowed social contacts. The bedding was made up of non-edible conifer wood shavings. Animals always had free access to water and salt blocks.

The forages used were two first-cut cocksfoot (Dactylis glomerata) hays, one leafy ( $L$ ) and one coarse $(C)$, harvested at two different stages of maturity (early and late cut). Their chemical characteristics, determined from samples collected throughout the experiment, are given in Table 1. In this table, values of organic matter digestibility refer to measurements made on sheep in pens with ad libitum feeding.

\section{Experimental design and procedure}

Each heifer had access to two adjacent troughs connected to a data processing system (Ingrand et al., 1998). The heifers were equipped with a halter carrying an electronic sensor indicating whether the animal's head was over the trough. The presence or absence of the heifer at the trough was checked automatically six times per minute. The troughs were placed on scales that were linked to a data processing system allowing the evolution of trough weight and thus the increase in intake over the day to be assessed. The weight of each trough was measured every minute, regardless of whether the animal's presence at the trough was detected or not.

We applied two constraints, one of physical accessibility to the leafy hay, and the other of temporal accessibility to both hays (daily access time to troughs). The physical constraint consisted in placing on the leafy hay a square weld mesh (bare steel grid) designed to constrain hay prehensibility by reducing bite size, in order to mimic the low height of a sward at pasture. The grid size was adjusted to the upper dimensions of the trough $(90 \times 44 \mathrm{~cm})$. The diameter of the wires forming the mesh was $5 \mathrm{~mm}$. The grid, placed on the surface of the food, was allowed to fall as the food was consumed. Tighteners fixed at each corner of the trough prevented the grid from being removed while the heifers were feeding. The grid was either absent or set at one of two different mesh sizes, i.e. $6 \times 6$ or $4 \times 4 \mathrm{~cm}$. These treatments are designated $L \infty, L 6$ and $L 4$ ( $L$ by reference to the leafy hay), respectively. The temporal constraint consisted in limiting the daily access time to the troughs and was applied on both hays. The daily access time was either free $(24 \mathrm{~h} /$ day) or restricted to $4 \mathrm{~h} /$ day (from 09:00 to 13:00 h). These two constraints were combined in a $3 \times 2$ factorial design

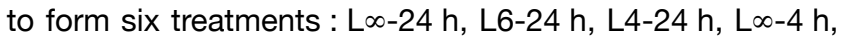
L6-4 $\mathrm{h}$ and L4-4 $\mathrm{h}$.

The experiment comprised eight 2-week-long periods (Table 2). Six of the periods were divided into two 1-week subperiods, the leafy hay being offered alone for the 1st week (with a given mesh size and access time, according to the treatment under study) then in choice with the coarse hay for the following week. The two other periods (nos. 1 and 5 , Table 2) consisted of offering the coarse hay alone, with or without the time constraint, according to the following time procedure. We allocated the six treatments to animals according to two successive $3 \times 3$ designs instead of one $6 \times 6$ Latin-square design, as shown in Table 2. Each $3 \times 3$ Latin square corresponded to a single access time so that each heifer successively experienced the different grids

Table 1 Chemical characteristics of experimental hays (average $\pm s . d$. over periods)

\begin{tabular}{|c|c|c|c|c|}
\hline & \multicolumn{2}{|c|}{ "Leafy hay (L) } & \multicolumn{2}{|c|}{ Coarse hay $(\mathrm{C})$} \\
\hline & Mean & s.d. & Mean & s.d. \\
\hline Dry matter (DM) (g/kg fresh weight) & 872 & $7 \cdot 5$ & 882 & $15 \cdot 2$ \\
\hline Crude protein (g/kg DM) & 107 & $2 \cdot 9$ & 61 & $4 \cdot 5$ \\
\hline Neutral-detergent fibre (g/kg DM) & 623 & $5 \cdot 7$ & 689 & $16 \cdot 5$ \\
\hline Acid-detergent fibre (g/kg DM) & 327 & $6 \cdot 5$ & 371 & $13 \cdot 3$ \\
\hline $\mathrm{OM}$ digestibility $\dagger$ & 0.657 & 0.0388 & 0.533 & 0.0313 \\
\hline
\end{tabular}

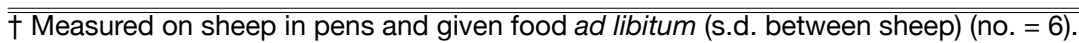




\section{Forage choices of cattle constrained by access and time}

Table 2 Succession of treatments for all heifers throughout the experiment $†$

\begin{tabular}{|c|c|c|c|c|c|c|}
\hline Animal & Heifer 1 & Heifer 2 & Heifer 3 & Heifer 4 & Heifer 5 & Heifer 6 \\
\hline Access time & & $4 \mathrm{~h} /$ day & & & 24 h/day & \\
\hline $\begin{array}{l}\text { Period } 1 \\
\text { (2 weeks) }\end{array}$ & C & C & C & C & C & C \\
\hline $\begin{array}{l}\text { Period } 2 \\
\text { week } 1 \\
\text { week } 2 \ddagger\end{array}$ & $\begin{array}{r}L \infty \\
L \infty / C\end{array}$ & $\begin{array}{r}\text { L6 } \\
\text { L6/C }\end{array}$ & $\begin{array}{r}\mathrm{L} 4 \\
\mathrm{~L} 4 / \mathrm{C}\end{array}$ & $\begin{array}{r}L_{\infty} \\
L_{\infty} / C\end{array}$ & $\begin{array}{r}\mathrm{L} 6 \\
\mathrm{~L} 6 / \mathrm{C}\end{array}$ & $\begin{array}{r}\mathrm{L} 4 \\
\mathrm{~L} 4 / \mathrm{C}\end{array}$ \\
\hline $\begin{array}{l}\text { Period } 3 \\
\text { week } 1 \\
\text { week } 2 \ddagger\end{array}$ & $\begin{array}{r}\mathrm{L} 4 \\
\mathrm{~L} 4 / \mathrm{C}\end{array}$ & $\begin{array}{r}L \infty \\
L \infty / C\end{array}$ & $\begin{array}{r}\text { L6 } \\
\text { L6/C }\end{array}$ & $\begin{array}{r}\mathrm{L} 4 \\
\mathrm{~L} 4 / \mathrm{C}\end{array}$ & $\begin{array}{r}L \infty \\
L \infty / C\end{array}$ & $\begin{array}{r}\text { L6 } \\
\text { L6/C }\end{array}$ \\
\hline $\begin{array}{l}\text { Period } 4 \\
\text { week } 1 \\
\text { week } 2 \ddagger\end{array}$ & $\begin{array}{r}\text { L6 } \\
\text { L6/C }\end{array}$ & $\begin{array}{r}\mathrm{L} 4 \\
\mathrm{~L} 4 / \mathrm{C}\end{array}$ & $\begin{array}{r}L_{\infty} \\
L \infty / C\end{array}$ & $\begin{array}{r}\text { L6 } \\
\text { L6/C }\end{array}$ & $\begin{array}{r}\mathrm{L} 4 \\
\mathrm{~L} 4 / \mathrm{C}\end{array}$ & $\begin{array}{r}L \infty \\
L \infty / C\end{array}$ \\
\hline & & 24 h/day & & & $4 \mathrm{~h} /$ day & \\
\hline $\begin{array}{l}\text { Period } 5 \\
\text { (2 weeks) }\end{array}$ & C & $\mathrm{C}$ & C & C & C & C \\
\hline $\begin{array}{l}\text { Period } 6 \\
\text { week } 1 \\
\text { week } 2 \ddagger\end{array}$ & $\begin{array}{r}L \infty \\
L \infty / C\end{array}$ & $\begin{array}{r}\text { L6 } \\
\text { L6/C }\end{array}$ & $\begin{array}{r}\mathrm{L} 4 \\
\mathrm{~L} 4 / \mathrm{C}\end{array}$ & $\begin{array}{r}\mathrm{L} \infty \\
\mathrm{L} \infty / \mathrm{C}\end{array}$ & $\begin{array}{r}\text { L6 } \\
\text { L6/C }\end{array}$ & $\begin{array}{r}\text { L4 } \\
\text { L4/C }\end{array}$ \\
\hline $\begin{array}{l}\text { Period } 7 \\
\text { week } 1 \\
\text { week } 2 \ddagger\end{array}$ & $\begin{array}{r}\mathrm{L} 4 \\
\mathrm{~L} 4 / \mathrm{C}\end{array}$ & $\begin{array}{r}L \infty \\
L \infty / C\end{array}$ & $\begin{array}{r}\text { L6 } \\
\text { L6/C }\end{array}$ & $\begin{array}{r}\mathrm{L} 4 \\
\mathrm{~L} 4 / \mathrm{C}\end{array}$ & $\begin{array}{r}L \infty \\
L \infty / C\end{array}$ & $\begin{array}{r}\text { L6 } \\
\text { L6/C }\end{array}$ \\
\hline $\begin{array}{l}\text { Period } 8 \\
\text { week } 1 \\
\text { week } 2 \ddagger\end{array}$ & $\begin{array}{r}\text { L6 } \\
\text { L6/C }\end{array}$ & $\begin{array}{r}\mathrm{L} 4 \\
\mathrm{~L} 4 / \mathrm{C}\end{array}$ & $\begin{array}{r}\mathrm{L} \infty \\
\mathrm{L} \infty / \mathrm{C}\end{array}$ & $\begin{array}{r}\text { L6 } \\
\text { L6/C }\end{array}$ & $\begin{array}{r}\mathrm{L} 4 \\
\mathrm{~L} 4 / \mathrm{C}\end{array}$ & $\begin{array}{r}\mathrm{L} \infty \\
\mathrm{L} \infty / C\end{array}$ \\
\hline
\end{tabular}

$\dagger \mathrm{L}$ and $\mathrm{C}$ represent leafy and coarse hays; $\infty, 6$ and 4 represent the mesh size of the grid (no grid, 6-cm wide mesh or 4 -cm wide mesh). $\ddagger$ On week 2 of periods $2,3,4,6,7$, and 8 , animals were offered a choice between $L$ and $C$.

for one given access time, then the same grids for the other access time, in order to prevent them from changing access time too often; this allowed them to anticipate the available time and adjust their behaviour accordingly. This experimental design was validated by the results of the first and fifth periods: when animals experienced a modification of access time, they needed about 5 to 6 days to stabilize intake. These first and fifth periods, when the coarse hay was offered alone for 2 weeks, allowed heifers to adapt to the new access time they were going to experience for the three following 2-week periods (each without, then with, choice).

The hays were distributed ad libitum once a day, at 09:00 h, their place in the troughs being alternated daily. A minimum of $2 \mathrm{~kg}$ of fresh matter of each hay was given each day, and proportionately 0.20 refusals were allowed when intake approached or exceeded $2 \mathrm{~kg}$.

\section{Behavioural measurements and sample collection}

The electronic detection system installed at the troughs enabled us to assess the total daily feeding times and their distribution throughout the day. Similarly, the electronic trough weighing system allowed us to follow the evolution of intake over the day. Daily intakes were also measured manually, by daily weighing of hay offered and refused, which allowed us to regularly check the reliability of the electronic weighing system. Individual intake data were adjusted linearly to a $450 \mathrm{~kg}$ heifer, by multiplying intake per $\mathrm{kg}$ of heifer weight at the considered period by 450 . Intake and feeding-time data allowed the preference for the leafy hay to be expressed as a proportion of total intake or total daily feeding time (choice ratios).
The hays offered were sampled on each of the last 4 days of each week. These samples were then bulked by week to be analysed for dry and organic matter, crude protein (Kjeldahl $\mathrm{N} \times 6 \cdot 25$ ), neutral-detergent fibre (NDF) and aciddetergent fibre (ADF, Komarek et al., 1994). These chemical characteristics are given in Table 1.

We also collected samples of heifers' faeces on the same days. Faeces were grouped by heifer and by week and analysed for their nitrogen content (Nf) in order to assess diet organic matter digestibility (OMD) using the equation proposed by Peyraud (1998) and given below:

$$
\mathrm{OMD}=0.975-0.00633 / \mathrm{Nf}
$$

(Nf expressed as a proportion of faecal organic matter).

The OMD of the leafy and the coarse hays (in the specific situation where there was neither a choice nor a constraint) thus obtained made it possible to estimate the digestible organic matter (DOM) intakes considered below.

\section{Statistical analyses}

We used the GLM procedure in the SAS statistical software package (Statistical Analysis Systems Institute, 1999). The situations of no choice and choice were analysed separately as they were not conducted on the same experimental weeks. Similarly, when there was not a choice, we first analysed the results obtained only with the leafy hay as the coarse hay was not offered at the same periods. However, since with several of the variables studied, the period had no effect, and for others its effect did not mean a progressive evolution with time, we repeated the data analysis by including the coarse hay without testing the period effect. Similarly, in 


\section{Ginane and Petit}

order to compare the no choice and choice situations, we repeated the data analysis including another factor, which was the situation (no choice or choice).

The data analysed were daily dry matter (DM) and DOM intakes, daily feeding times, DOM intake rates on each hay, diet digestibility estimated from faecal $\mathrm{N}$ content and, when there was a choice, the choice ratios (proportion of DM and DOM intake and feeding time). These ratios were angular transformed (arcsinus) to stabilize variance. Whether or not there was a choice, we tested the effect of grid mesh size, access time, and their interaction, period and heifer

\section{Results}

Whether the analysis concerned the situation where there was or was not a choice, we did not detect any effect of the $6-\mathrm{cm}$ mesh size compared with the no grid situation, whatever the studied variables. Therefore, it is not the grid itself but only the reduced size of its mesh that constituted a constraint to animals. Furthermore, for all studied variables, a first interesting result is that the interaction between the physical and the temporal constraints was never significant.

\section{When there was not a choice}

As expected, the 4-cm mesh size significantly reduced DOM intake rates on the leafy hay $(P<0.001)$ whatever the access time (Figure 1d). However, heifers did not compensate by increasing their daily feeding time in 24-h access $(P>0.05)$ (Figure $1 \mathrm{~b}$ ). When given 4-h access, animals spent between 0.88 and 0.92 of the allowed time feeding according to the

(a)

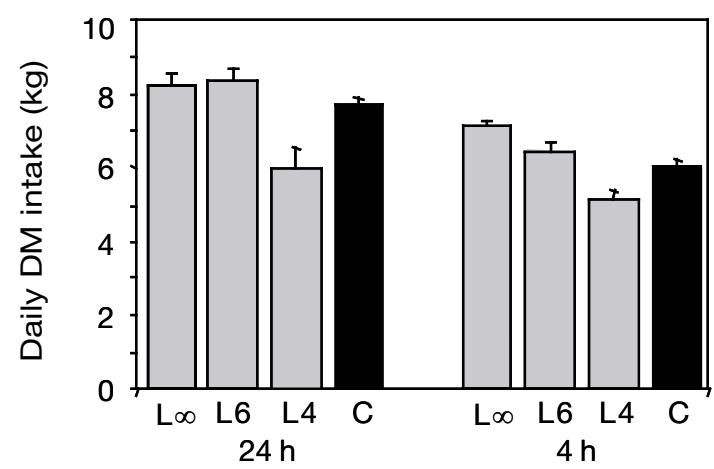

(c)

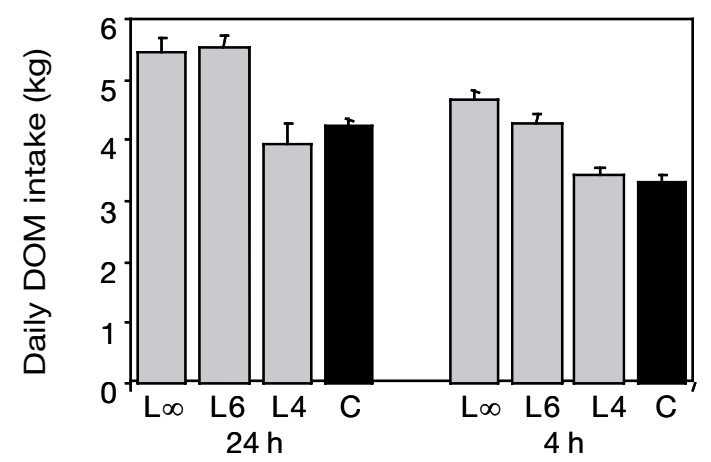

physical constraint, and actual daily feeding times were reduced by about 0.40 compared with free access time $(P<0.001)$. This significant reduction was accompanied by a significant increase in intake rates on $L(P<0 \cdot 001)$, whatever the physical constraint (Figure 1d). We observed that on L4 from 24-h to 4-h access, heifers managed to increase their intake rate nearly as much as on $L 6$ or $L \infty$, which represents a proportionately greater increase $(0.40 v .0 .31)$. The 4-cm mesh size significantly reduced DM and DOM intakes $(P<0.001)$ by about $0 \cdot 25$, whatever the access time (Figure 1a and $\mathrm{c}$ ). Despite the intake rate adjustments made by heifers, the access time constraint also reduced daily DM and DOM intakes $(P<0.001)$, by 0.14 on $L \infty$ and $L 4$ and by 0.22 on L6. Lastly, the grid slightly reduced the OMD of the diet $(P<0.01)$, even at the $6-\mathrm{cm}$ mesh size and whatever the access time (Table 3), possibly due to it being more difficult for animals to sort the better elements within the leafy hay when a grid was in place. The temporal constraint did not affect diet OMD $(P>0 \cdot 05)$ (Table 3).

With the coarse hay included in the analysis, it appears that, as on $\mathrm{L}$, the reduction of access time led on $\mathrm{C}$ to an increase in intake rate $(P<0.01)$ (Figure $1 \mathrm{~d})$ and to a decrease in intake $(P<0.001)$ (Figure 1a and $\mathrm{c})$. Whatever the access time, the heifers, as expected, ingested $\mathrm{C}$ at a significantly lower rate than $\mathrm{L} \infty$ or L6 $(P<0.001)$, but at a similar rate to $\mathrm{L} 4(P>0.05)$ (Figure 1d). DM intake on $C$ was significantly lower than on $\mathrm{L} \infty$ or L6, especially with $4-\mathrm{h}$ access, and higher than on L4 $(P<0.001)$ (Figure 1a). However, DOM intakes were similar on $\mathrm{C}$ to those on $\mathrm{L} 4$ and lower than on $\mathrm{L} \infty$ and $\mathrm{L} 6$, regardless of access time $(P<0 \cdot 001)$ (Figure 1c).

(b)

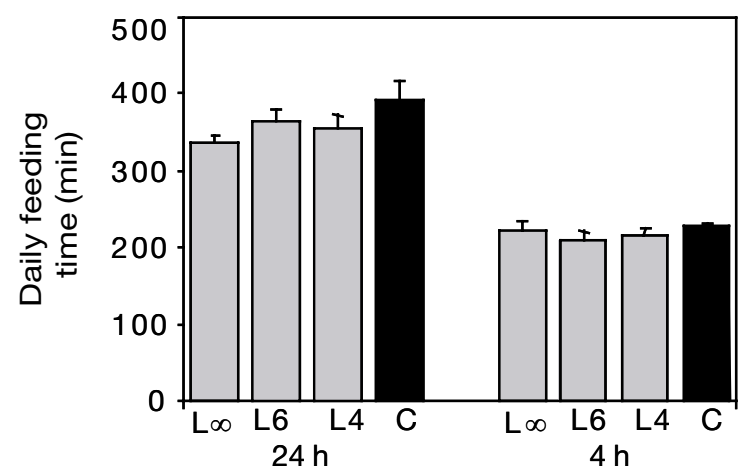

(d)

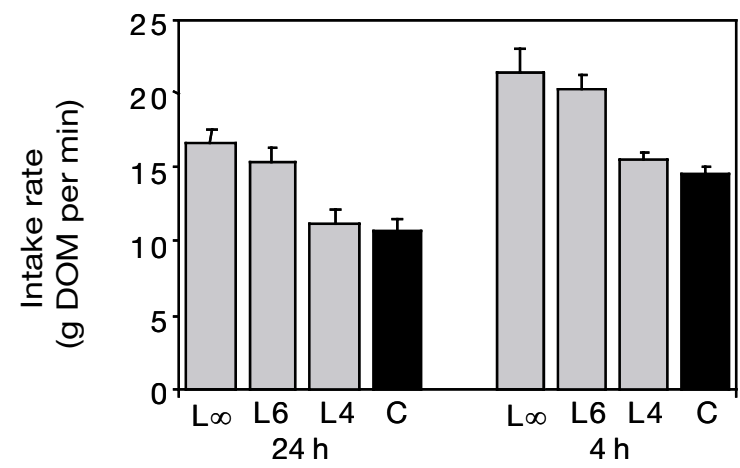

Figure 1 Daily dry matter (DM) intake (a), feeding time (b), digestible organic matter (DOM) intake (c) and DOM intake rate (d) (mean \pm s.e.) on leafy ( $\mathrm{L}$, grey bar) and coarse (C, black bar) hays when offered alone, according to physical (L $\infty$ : no grid, L6 and L4: grid with 6-cm or 4-cm mesh size, respectively) and temporal constraints ( $24 \mathrm{~h}$ or $4 \mathrm{~h}$ of access daily). 


\section{Forage choices of cattle constrained by access and time}

When there was a choice

The heifers maintained their preferences for the leafy hay with the restriction of access time, whether these choices were expressed in terms of DM or DOM intake ratio (Figure $2 a$ and c) or feeding time ratio (Figure $2 b)(P>0.05)$. It should be noted however that preferences were slightly increased with $\mathrm{L} \infty$ and $\mathrm{L} 6$ while they were slightly decreased with L4. The temporal constraint reduced daily intake of DM or DOM $(P<0.001)$ (Figure 1a, $\mathrm{c})$, but this reduction was limited to about proportionately 0.17 as the reduction of total feeding time $(P<0.001)$ (Figure $1 \mathrm{~b})$ was accompanied by a considerable increase in intake rate not only on the leafy $(P<0.001)$ but also on the coarse hay $(P<0.001)$ (Figure $2 d)$. The greatest increase in intake rate was observed on $L 4$ (proportionately +0.62 ) and the intake rate of $C$ was also the highest when associated with $L 4(P<0.01)$.

The physical constraint significantly reduced the preference for the leafy hay $(P<0.001)$, by decreasing feeding time on $\mathrm{L}(P<0.001)$ and increasing feeding time on $\mathrm{C}(P<0.001)$, without a significant increase in total feeding time $(P>0.05)$ (Figure $2 b$ ). These modifications appeared more pronounced in 4-h than in 24-h access, despite a non-significant interaction between constraints $(P>0.05)$, as in 24-h access the decrease in feeding time on $L$ was weak and non-significant $(P>0 \cdot 05)$. Expressed as a DM or DOM intake ratio, the results were similar, except that in both 24-h and 4$h$ access, the intake of $L$ was significantly lower with $L 4$ than with $L \infty$ or $L 6(P<0 \cdot 001)$ (Figure $2 a, c)$ due to lower intake rate on $L 4$ than on $L \infty$ or $L 6$. The physical constraint significantly affected DOM intake rates, which were reduced for the leafy

(a)

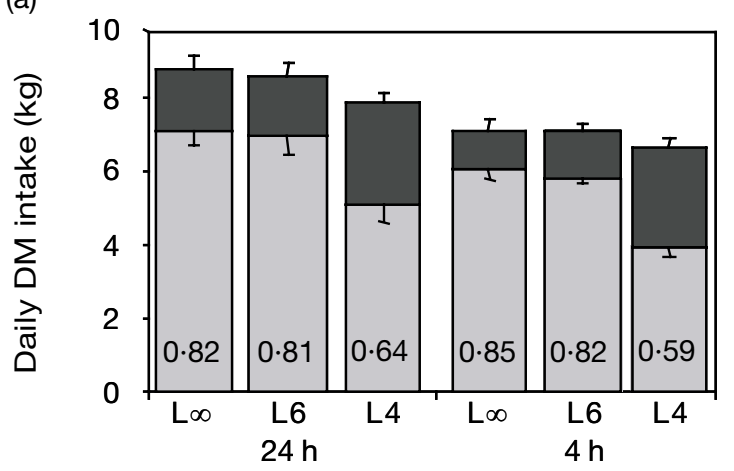

(c)

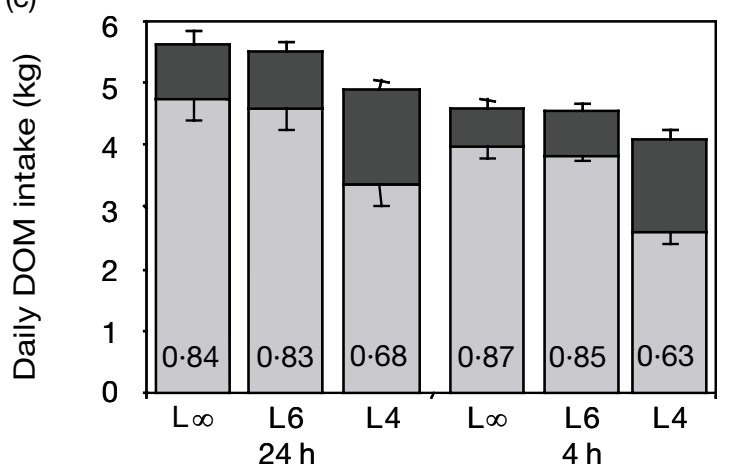

hay with the $4-\mathrm{cm}$ mesh size $(P<0.001)$ and slightly more in 24-h $(P<0.001)$ than in $4-\mathrm{h}$ access $(P<0.01)$ (Figure $2 \mathrm{~d})$. It is worth noting that the intake rate of $L$ was higher in treatment L4-4 $\mathrm{h}$ than in $\mathrm{L} \infty-24 \mathrm{~h}(P<0 \cdot 001)$. In contrast, intake rates on the coarse hay increased with the increasing physical constraint $(P<0.05)$, whatever the access time. The physical constraint to access $L$ significantly but moderately reduced total DM and DOM intake $(P<0.001)$, whatever the access time (Figure 2a and c).

Lastly, the physical constraint, which decreased the preference for the leafy hay, reduced diet OMD $(P<0.001)$ by 0.015 in 24-h access and by 0.034 in 4-h access (Table 3 ). Conversely, the temporal constraint, which did not modify the choice for $\mathrm{L}$, did not significantly modify diet $\mathrm{OMD}(P>0.05)$, despite the slight decrease for L4 (-0.015) (Table 3).

Comparison of situations where there was or was not a choice

Whatever the intensity of the physical constraint, the heifers lengthened their total daily feeding time when there was a choice compared with when there was not ( $L$ alone), whenever they had the opportunity to do so (24-h access) (situation $\times$ access time, $P<0 \cdot 01$ ).

In treatments $L \infty$ and $L 6$, animals decreased their feeding time on $L$ when there was a choice $(P<0.001)$ in both 4$h$ and 24-h access, without substantially and significantly increasing their intake rate on this leafy hay $(P>0.05)$. They devoted a non-negligible part of their feeding time to the coarse hay, which was ingested at a slightly lower rate in the

(b)

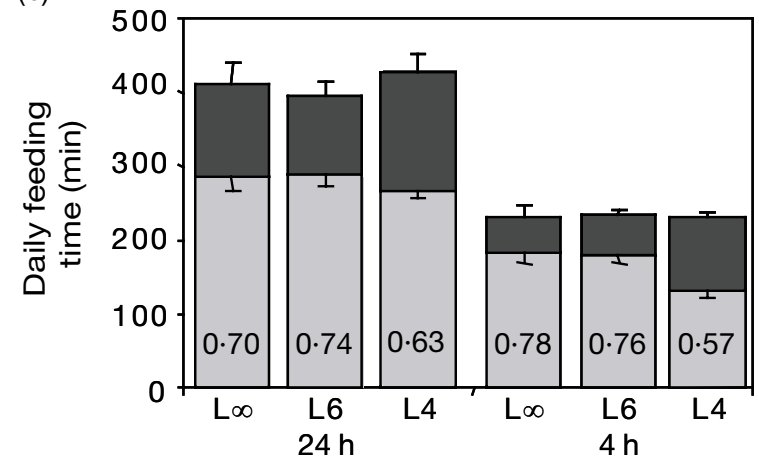

(d)

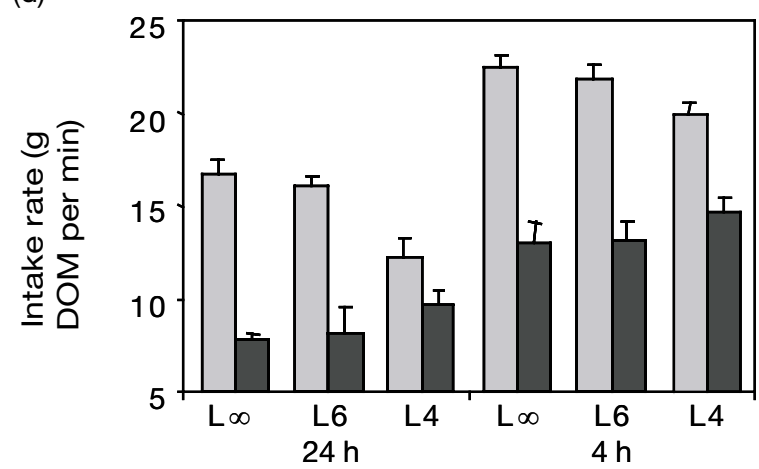

Figure 2 Daily dry matter (DM) intake (a), feeding time (b), digestible organic matter (DOM) intake (c) and DOM intake rate (d) (mean \pm s.e) on leafy ( $\mathrm{L}$, grey bar) and coarse (C, black bar) hays when offered in a choice situation, according to physical (Lœ: no grid, L6 and L4: grid with 6-cm or 4 -cm mesh size, respectively) and temporal constraints ( $24 \mathrm{~h}$ or $4 \mathrm{~h}$ of access daily).

Choice ratios for $L$ (proportion of total intake or total feeding time) are indicated within the bars in (a), (b) and (c). 


\section{Ginane and Petit}

Table 3 Organic matter digestibility (mean \pm s.e.) of the diet when the hays (leafy $(L)$ and coarse $(C))$ were offered either alone or in a choice situation according to physical and temporal constraints $\dagger$

\begin{tabular}{|c|c|c|c|c|c|c|c|c|}
\hline & \multicolumn{4}{|c|}{ Free access time (24 h) } & \multicolumn{4}{|c|}{ Restricted access time (4 h) } \\
\hline & $L \infty$ & L6 & L4 & $\mathrm{C}$ & $L \infty$ & L6 & L4 & C \\
\hline No choice & $\begin{array}{l}0.739 \\
(0.0015)\end{array}$ & $\begin{array}{l}0.733 \\
(0.0060)\end{array}$ & $\begin{array}{l}0 \cdot 717 \\
(0 \cdot 0073)\end{array}$ & $\begin{array}{l}0.588 \\
(0.0069)\end{array}$ & $\begin{array}{l}0.736 \\
(0.0042)\end{array}$ & $\begin{array}{l}0.720 \\
(0.0030)\end{array}$ & $\begin{array}{l}0.724 \\
(0.0055)\end{array}$ & $\begin{array}{l}0.589 \\
(0.0094)\end{array}$ \\
\hline Choice & $\begin{array}{l}0.710 \\
(0.0065)\end{array}$ & $\begin{array}{l}0.707 \\
(0.0066)\end{array}$ & $\begin{array}{l}0.695 \\
(0.0045)\end{array}$ & $\begin{array}{l}- \\
-\end{array}$ & $\begin{array}{l}0.714 \\
(0.0082)\end{array}$ & $\begin{array}{l}0.704 \\
(0.0062)\end{array}$ & $\begin{array}{l}0.680 \\
(0.0024)\end{array}$ & $\begin{array}{l}- \\
-\end{array}$ \\
\hline
\end{tabular}

† Physical constraints: L $\infty$, no grid; L6 and L4, grid with 6-cm and 4-cm mesh size, respectively. Temporal constraints: $24 \mathrm{~h}$ or $4 \mathrm{~h}$ of access daily.

$\ddagger$ In the choice situation, the digestibility is that of $L$ and $C$ combined.

choice than in the no choice situation $(P<0 \cdot 05)$. Therefore, total DM and DOM intakes were not significantly increased by giving choice when the constraint on $L$ was absent or weak $(L \infty, L 6)(P>0 \cdot 05)$, whatever the access time, contrary to the most constraining treatment ( $L 4$, see below) (situation $\times$ grid, $P<0.01)$.

When there was a significant physical constraint (L4), giving choice also decreased the feeding time on $L$ whatever the access time, as in treatments $L \infty$ and $L 6$, but at the same time increased intake rate on $L(P<0.01)$, particularly in $4-h$ access. The heifers devoted a great part of their feeding time to the coarse hay and ingested it nearly as fast as when it was offered alone $(P>0 \cdot 05)$. Therefore, they ingested more DM and DOM when offered a choice, whatever the access time $(P<0 \cdot 001)$.

Whatever the physical constraint, the ingestion of both hays in choice led to a decrease in diet digestibility $(P<0.001)$ compared with the situation where only $L$ was offered (Table $3)$.

\section{Discussion}

In this indoor experiment, we used a grid to reduce the accessibility of the leafy hay, in order to mimic the low height of vegetative sward at pasture. We combined this constraint with a temporal constraint to test the motivation of heifers to keep ingesting the leafy hay, which they preferred, when it was offered with another lower quality but physically more accessible hay. We used the optimal foraging theory (Stephens and Krebs, 1986) as a theoretical framework, as the optimization approach enables quantitative prediction of choices and provides a reference for comparison with observed diet choices.

\section{The grid to reduce intake rates}

One of the main currencies considered to be maximized by herbivores is the energy intake rate (EIR) of forages (Stephens and Krebs, 1986). Our predictions supposed that we managed to make EIR lower on $L$ with the finest grid mesh size (L4) than on C, to create a trade-off between short-term rate of food intake (i.e. 'quantity', by selecting C) and long-term rate of energy assimilation (i.e. 'quality', by selecting L).

The finest mesh size (L4) managed to reduce the intake rate of $L$, and in line with the predictions, choice for $L$ decreased when the smallest mesh size was applied. However, we did not manage to make EIR on L4 lower than on C because the animals demonstrated an interesting capacity to modulate their intake rate on this hay despite the grid. A width of 4 $\mathrm{cm}$ would nevertheless represent about half of the estimated incisor arcade breadth of 450-kg body weight cattle (Illius and Gordon, 1987), and it appears that the 4-cm-wide mesh did indeed constrain the animals. The clearest evidence for this is that total daily intake in an absence of choice was lower on $L 4$ than on $L \infty$ or $L 6$, whatever the access time. It seems that animals 'get tired' of collecting the leafy hay through this grid, as shown by the fact that (i) in 24-h access they did not extend their feeding time on $L$ when the physical constraint was intensified and the intake rate went down, while the reverse is often observed with other physical constraints such as short grass height (Penning, 1986; Penning et al., 1991; Rook et al., 1994; Ginane et al., 2003), and (ii) the preference for $\mathrm{L}$ in treatment $\mathrm{L} 4-4 \mathrm{~h}$ progressively declined from 0.80 to 0.45 over the 4 hours. This indicates that a physical constraint may not be expressed solely in terms of a decrease in intake rate but also in terms of a loss of animal motivation, more difficult to assess, but which was here made evident with the smallest grid mesh size.

Indeed, heifers greatly modified their absolute and relative intake rates of forages according to the measurement conditions (choice or no choice, measurement time scale, etc.). For example, when there was not a choice, on the basis of the allocated 4 or $24 \mathrm{~h}, \mathrm{~L} 4$ was ingested at the same rate as $C$, but over the 1 st hour of feeding it was ingested faster $(+5.8 \mathrm{~g}$ DOM per min in 24-h access and $+4.5 \mathrm{~g} /$ min in 4-h access). Again, intake rate on L4 ranged from $11.1 \mathrm{~g}$ DOM per min when there was no choice with 24-h access to $15.5 \mathrm{~g} / \mathrm{min}$ with 4-h access, then up to $19.9 \mathrm{~g} /$ min in choice with 4-h access. Intake rate was then higher with maximal than minimal constraints ( $L \infty$ or $L 6$ with $24-\mathrm{h}$ access), and very close to the value of $22.4 \mathrm{~g}$ DOM per min expressed while $L$ was freely accessible with $4-h$ access in choice. Intake rate on $L 4$ even reached $25.4 \mathrm{~g}$ DOM per min during the first hour of feeding in choice with 4-h access. This great flexibility of heifers in increasing their intake rate on $L$ was probably made possible by the fact that the leafy structure of $L$ required few mastication cycles during eating. Either way, this underlines their motivation to favour the better quality forage, including when it was offered in choice while they could consume the freely accessible coarse hay. In comparison, the coarse hay was ingested at the same rate whether or not there was a choice (with L4), under 4-h access. This great flexibility in behaviour stresses the limit of using the notion of fixed constraints when they are 


\section{Forage choices of cattle constrained by access and time}

expressed by means of behavioural variables, as pointed out by Illius and Gordon (1999), and may make comparison difficult between observed diet choices and predictions from a theory based on these behavioural variables (relative energy intake rates between forages).

\section{The L4-C choice : the benefit of having choice}

While foraging, herbivores are confronted with diverse constraints and are supposed to make choices resulting from the balance of costs and benefits. In the present study, it appears that the intake of L4 was constrained by its cropping cost (lower daily DM intake on L4 than on C offered alone) as was the one of $\mathrm{C}$ by its rates of chewing and digestion (lower digestibility of $C$ than of $L$ ), with similar daily DOM intakes with either L4 or $\mathrm{C}$ at the end of the day. Thus, the heifers may have maximized either diet quality or DM intake by mainly selecting $L 4$ or $C$ respectively, with a similar resulting DOM intake. In fact, the choice expressed in terms of proportion of feeding time was slightly in favour of $L$ (about 0.6 whatever the access time). This behaviour is interesting because it enabled heifers to ingest more DOM all in all than when L4 or C were offered alone $(4.9 \mathrm{~kg}$ in choice v. 3.9 and $4.2 \mathrm{~kg}$ with $24-\mathrm{h}$ access, and 4.1 v. 3.4 and $3.3 \mathrm{~kg}$ with $4-\mathrm{h}$ access). The increase in intake in the choice situation has already been shown in different contexts, with sheep grazing grass and clover (Champion et al., 2004) or with heifers feeding on hays of different quality (Ginane et al., 2002). Here, it is mainly the result of an inverse relationship between decreasing time spent feeding on L4 and increasing intake rate on this hay. While spending less time feeding on $L$ in choice than in no choice, the heifers ingested it much faster, especially when the access time was restricted (12.3 v. $11.1 \mathrm{~g}$ DOM per min with 24-h access and $19.9 \mathrm{v} .15 .5 \mathrm{~g} / \mathrm{min}$ with 4-h access), while intake rate on $\mathrm{C}$ remained stable $(9.8 \mathrm{v} .10 .8 \mathrm{~g} / \mathrm{min}$ and $14.7 \mathrm{v} .14 .5 \mathrm{~g} / \mathrm{min}$ with 24-h and 4-h access respectively). Thus, even if heifers showed a great interest in $\mathrm{L}$, in a very constraining situation (L4-4 h) they did not prioritize their diet quality by ingesting $L$ in great amounts. Rather, they chose to divide their feeding time between the two hays and to manage their intake rate so that they increased their total DOM intake in the choice situation, with a resultant diet digestibility between those obtained with either L4 or C offered alone. These results therefore agree with the conclusions rising from a growing body of grazing experiments stating that the observed diet choices of ruminants faced with heterogeneous swards with low availability of good forages would have to provide a maximal daily DOM intake (WallisDeVries and Daleboudt, 1994; Wilmshurst et al., 1995; Hirata et al., 2002).

\section{Mixed diets : the case of $L \infty-C$ and $L 6-C$}

When $L \infty$ or $L 6$ and $C$ were presented together, the optimal choice must have been mainly or indeed exclusively in favour of $L$, as the heifers could maximize both diet quality and DM or DOM intake by feeding only on L. However, the heifers always deliberately included $\mathrm{C}$ in their diet in non-negligible proportions. With 24-h access, the increase in total feeding time when there was a choice allowed heifers to maintain DOM intake compared with when the leafy hay was offered alone. Unexpectedly, the restriction of access time only slightly increased the choices for $L$, but the higher intake rates of both hays on 4-h than on 24-h access allowed DOM intakes with 4-h access to be similar when there was or was not a choice. Mixed diets are a general rule in ruminant feeding behaviour, and various theories, some linked to the animal's cognitive abilities, have been put forward to explain this deviation from optimal choice.

The leafy and the coarse hays were different in chemical composition, digestibility and probable sensorial characteristics. Therefore, the observed diet diversity may result from the will to maintain an adequate ruminal and/ or nutritional balance (Westoby, 1978; Cooper et al., 1995 and 1996). The need to regularly sample foods to update information (Illius and Gordon, 1990; Provenza and Balph, 1990) must have had a lower influence as animals were used to the hays and treatments for several days before data were recorded. Finally, the observed mixed diets can also be interpreted as the pleasure of ingesting diversified foods with different sensorial characteristics (Rolls, 1986). We can only speculate on the respective influences of these theories in explaining the observed mixed diets. They may all have contributed to the deviation from predictions, resulting in the great proportion of feeding time and intake recorded on C.

The results showed that in a very constraining situation where daily intake may be very low (L4-4 h), the heifers when offered a choice shared their feeding time among both hays and managed their intake rates in such a way that they were able to increase their total daily DOM intake compared with when either of the hays were offered alone. In a less constraining situation ( $\mathrm{\infty} \infty$ or L6-4 h), the heifers expressed a clear intent to mix their diet and did not maximize their total daily DOM intake.

It appeared difficult to mimic indoors, with the grid, a physical grazing constraint such as sward height. The small mesh size of the grid constrained animals (by decreasing their motivation), but was not expressed, as has been shown to be the case outdoors, by a clear drop in intake rate compared with the more accessible alternative forage of lower quality. This may stem from the fact that on short grass, the necessity for the grazer to walk and move its head between small bites probably prevents it from compensating the small bite mass by increasing bite rate as much as on the finest-size mesh grid. The indoor experiment nevertheless carries many advantages as it can easily provide useful data to explain choices (e.g. intake, intake rate and feeding time recorded when the food options are offered alone) and provide information on the relative weights of behavioural adaptations (intake rate, feeding time) in constraining situations. In the present experiment, it notably revealed the heifers' capacity to modulate their intake rate on L, to keep ingesting this hay of better quality and to increase their total daily DOM intake in a very constraining situation. Therefore, indoor studies represent useful complements to grazing studies for understanding the behavioural mechanisms involved in ruminant food selection and ingestion at pasture.

\section{Acknowledgements}

The authors are grateful to B. Sepchat and J. Tyssandier for care and management of the experimental animals, A. Le Morvan for data processing, J. Jamot for sample treatment and chemical analyses and T. Vimal for electronic system maintenance. 


\section{References}

Allden, W. G. and Whittaker, I. A. 1970. The determinants of herbage intake by grazing sheep: the interrelations of factors influencing herbage intake and availability. Australian Journal of Agricultural Research 21: 755-766.

Black, J. L. and Kenney, P. A. 1984. Factors affecting diet selection by sheep. II. Height and density of pasture. Australian Journal of Agricultural Research 35: 565-578.

Champion, R. A., Orr, R. J., Penning, P. D. and Rutter, S. M. 2004. The effect of the spatial scale of heterogeneity of two herbage species on the grazing behaviour of lactating sheep. Applied Animal Behaviour Science 88: 61-76.

Chilibroste, P., Tamminga, S. and Boer, H. 1997. Effects of length of grazing session, rumen fill and starvation time before grazing on dry-matter intake, ingestive behaviour and dry-matter rumen pool sizes of grazing lactating dairy cows. Grass and Forage Science 52: 249-257.

Cooper, S. D. B., Kyriazakis, I. and Nolan, J. V. 1995. Diet selection in sheep: the role of the rumen environment in the selection of a diet from two feeds that differ in their energy density. British Journal of Nutrition 74: 39-54.

Cooper, S. D. B., Kyriazakis, I. and Oldham, J. D. 1996. The effects of physical form of feed, carbohydrate source, and inclusion of sodium bicarbonate on the diet selections of sheep. Journal of Animal Science 74: 1240-1251.

Coughenour, M. B. 1991. Spatial components of plant-herbivore interactions in pastoral, ranching and native ungulate ecosystems. Journal of Range Management 44: 530-542.

Dumont, B. and Petit, M. 1995. An indoor method for studying the preferences of sheep and cattle at pasture. Applied Animal Behaviour Science 46: 67-80.

Ginane, C. and Petit, M. 2005. Constraining the time available to graze reinforces heifers' preference for sward of high quality despite low availability. Applied Animal Behaviour Science. In press.

Ginane, C., Petit, M. and D'Hour, P. 2003. How do grazing heifers choose between maturing reproductive and tall or short vegetative swards? Applied Animal Behaviour Science 83: 15-27.

Ginane, C., Petit, M. and D'Hour, P. 2003. How do grazing heifers choose between maturing reproductive and tall or short vegetative swards? Applied Animal Behaviour Science 83: 15-27.

Gordon, I. J. and Illius, A. W. 1992. Foraging strategy: from monoculture to mosaic. In Progress in sheep and goat research (ed. A. W. Speedy), pp. 153-177. CAB International, Wallingford.

Hidari, H. 1981. The relationships between rumen load and diurnal eating pattern of sheep fed in various time of access to feed. Japanese Journal of Zootechnical Science 52: 219-226.

Hirata, M., Sato, R. and Ogura, S. I. 2002. Effects of progressive grazing of a pasture on the spatial distributions of herbage mass and utilization by cattle: a preliminary study. Ecological Research 17: 381-393.

Iason, G. R., Mantecon, A. R., Sim, D. A., Gonzalez, J., Foreman, E., Bermudez, F. F. and Elston, D. A. 1999. Can grazing sheep compensate for a daily foraging time constraint? Journal of Animal Ecology 68: 87-93.

Illius, A. W. and Gordon, I. J. 1987. The allometry of food intake in grazing ruminants. Journal of Animal Ecology 56: 989-999.

Illius, A. W. and Gordon, I. J. 1990. Constraints on diet selection and foraging behaviour in mammalian herbivores. In Behavioural mechanisms of food selection (ed. R. N. Hughes), pp. 369-392. Springer-Verlag Berlin Heidelberg.

Illius, A. W. and Gordon, I. J. 1999. The physiological ecology of mammalian herbivory. In Nutritional ecology of herbivores (ed. H. G. Jung and G. C. Fahey), fifth international symposium on the nutrition of herbivores, San Antonio, Texas, pp. 71-96.

Ingrand, S., Vimal, T., Fléchet, J., Agabriel, J., Brun, J. P., Lassalas, J. and Dedieu, B. 1998. A free-access system for the long-term monitoring of individual intake of beef cows kept in a group. Proceedings of the IXth European intake workshop, Institute of Grassland and Environmental Research, North Wyke, UK, pp. 17-20.
Kenney, P. A. and Black, J. L. 1984. Factors affecting diet selection by sheep. I. Potential intake rate and acceptability of feed. Australian Journal of Agricultural Research 35: 551-563.

Komarek, A. R., Fairport NY ANKOM Co., Robertson, J. B. and Van Soest, P. J. 1994. A comparison of methods for determining ADF using the filter bag technique versus conventional filtration. Journal of Animal Science 72: (suppl. 1) 114.

Kyriazakis, I. and Oldham, J. D. 1993. Diet selection in sheep: the ability of growing lambs to select a diet that meets their crude protein (nitrogen $\times 6 \cdot 25$ ) requirements. British Journal of Nutrition 69: 617-629.

Laca, E. A., Ortega, I. M. and Soca, P. 1997. Controlling diet selection of sheep by restricting eating time. Proceedings of the 50th annual meeting of the Society for Range Management, p. 30.

Laca, E. A., Ungar, E. D., Seligman, N. and Demment, M. W. 1992. Effects of sward height and bulk density on bite dimensions of cattle grazing homogeneous swards. Grass and Forage Science 47: $91-102$.

Newman, J. A., Parsons, A. J., Thornley, J. H. M., Penning, P. D. and Krebs, J. R. 1995. Optimal diet selection by a generalist grazing herbivore. Functional Ecology 9: 255-268.

Penning, P. D. 1986. Some effects of sward conditions on grazing behaviour and intake by sheep. In Grazing research at northern latitudes (ed. O. Gudmundsson), pp. 219-226. Plenum Publishing Co., NY.

Penning, P. D., Parsons, A. J., Orr, R. J. and Treacher, T. T. 1991. Intake and behaviour responses by sheep to changes in sward characteristics under continuous stocking. Grass and Forage Science 46: 15-28.

Peyraud, J. L. 1998. Techniques for measuring faecal flow, digestibility and intake of herbage in grazing ruminants. Proceedings of the ninth European intake workshop, North Wyke, UK, pp. 39-43.

Provenza, F. D. and Balph, D. F. 1990. Applicability of five dietselection models to various foraging challenges ruminants encounter. In Behavioural mechanisms of food selection (ed. R. N. Hughes), pp. 424-460. Springer-Verlag, Berlin.

Rolls, B. J. 1986. Sensory-specific satiety. Nutritional Review 44: 93-101.

Romney, D. L., Sendalo, D. S. C., Owen, E., Mtenga, L. A., Penning, P. D., Mayes, R. W. and Hendy, C. R. C. 1996. Effects of tethering management on feed intake and behaviour of Tanzanian goats. Small Ruminant Research 19: 113-120.

Rook, A. J., Huckle, C. A. and Penning, P. D. 1994. Effects of sward height and concentrate supplementation on the ingestive behaviour of spring-calving dairy cows grazing grass-clover swards. Applied Animal Behaviour Science 40: 101-112.

Scott, L. L. and Provenza, F. D. 1998. Variety of foods and flavors affects selection of foraging location by sheep. Applied Animal Behaviour Science 61: 113-122.

Statistical Analysis Systems Institute. 1999. SAS/STAT user's guide, version 8 . SAS Institute Inc., Cary, NC.

Stephens, D. W. and Krebs, J. R. 1986. Foraging theory. Princeton University Press, Princeton, NJ.

Suzuki, S., Shinde, Y. and Hidari, H. 1970. Effects of change in the daily time of access to hay on the rate of eating and feed intake of dairy cows. Japanese Journal of Zootechnical Science 41: 423-429.

WallisDeVries, M. F. and Daleboudt, C. 1994. Foraging strategy of cattle in patchy grassland. Oecologia 100: 98-106.

Westoby, M. 1978. What are the biological bases of varied diets? The American Naturalist 112: 627-631.

Willms, W. D., Dormaar, J. F. and Schaaltje, G. B. 1988. Stability of grazed patches on rough fescue grasslands. Journal of Range Management 41: 503-508.

Wilmshurst, J. F., Fryxell, J. M. and Hudson, R. J. 1995. Forage quality and patch choice by wapiti (Cervus elaphus). Behavioural Ecology 6: 209-217.

(Received 6 July 2004 - Accepted 31 March 2005) 